\title{
İşbirlikli Öğrenmenin Sosyal Bilgiler Öğretmen Adaylarının Mesleki Bilgi ve Becerilerine Etkisi
}

\section{The Effect of Cooperative Learning on Preservice Social Studies Teachers' Professional Knowledge and Skills}

\author{
Vural TÜNKLER ${ }^{1}$
}

\section{Öz}

Bu çalışmada, işbirlikli öğrenmenin sosyal bilgiler öğretmen adaylarının mesleki bilgi ve becerileri üzerindeki etkisi incelenmeye çalışılıştır. Ayrıca öğretmen adaylarının işbirlikli öğrenmeye yönelik görüşleri belirlenmiştir. Karma yöntemin yakınsayan paralel desenine dayanan araştırmanın nicel boyutunda sontest eşleştirilmiş kontrol gruplu desen uygulanırken, nitel boyutta olgubilim deseni kullanılmıştır. Veriler Öğretmenlik Uygulaması Dersi Öğretmen Adayı Akran Değerlendirmesi Ölçeği ile yansıtıcı günlüklerden elde edilmiştir. Araştırma sonucunda işbirlikli öğrenmenin geleneksel grup çalışmasına göre öğretmen adaylarının mesleki bilgi ve becerileri üzerinde daha fazla etkili olduğu tespit edilmiştir. Öğretmen adaylarının işbirlikli öğrenmeye yönelik görüşlerinin olumlu yönde olduğu görülmüştür.

Anahtar Kelimeler: İ̧̧birlikli öğrenme, mesleki bilgi ve beceriler, öğretmen adayları, sosyal bilgiler

\section{Abstract}

In this study was studied the contribution of the cooperative learning on preservice social studies teachers' professional knowledge and skills. In addition, were investigated the opinions of preservice teachers on cooperative learning. The study depends on mixed method research. The data were obtained by reflective diaries with the Peer Assessment Scale for Activities of Teaching Practice Course. As a result of the research, it was determined that cooperative learning was more effective on the professional knowledge and skills of preservice teachers according to the traditional group work. The opinions of preservice teachers on cooperative learning were found to be positive.

Keywords: Cooperative learning, professional knowledge and skills, preservice teachers, social studies 


\section{Extended Abstract}

Purpose: The purpose of this study is to investigate the effects of cooperative learning on the professional knowledge and skills of preservice social studies teachers. Moreover, views of the preservice teachers concerning cooperative learning were also determined within the scope of the study.

Method: The study was conducted on preservice teachers in the senior year at the Social Studies Teaching Department of a state university in Turkey. Posttest control group design, one of the quasi-experimental designs, was employed in the quantitative dimension of this study, which was conducted in accordance with the convergent parallel design of the mixed method, whereas phenomenology design was used in the qualitative dimension. The research data were collected using the Peer Assessment Scale for Activities of Teaching Practice Course (PASATPC), which was developed by Bektaş, Horzum and Ayvaz (2010), and reflective diaries prepared by the participants. PASATPC is composed of the factors of "teaching process", "communication and assessment", "preparing for the course and relating the course" "classroom management" and "feedback". The preservice teachers who were in the experimental group where cooperative learning was implemented were asked to prepare reflective diaries in which they would express their views regarding cooperative learning. They were expected to state in the diaries the processes and situations (such as establishing communication and interaction, planning the teaching, and managing the teachinglearning process) which they had experienced during the group work. Independent sample t-test and Mann Whitney $U$ test were used to analyze the quantitative data obtained from the study and Kendall's concordance coefficient (W) was calculated. The qualitative data, on the other hand, were analyzed using the descriptive analysis technique. The study was conducted during the Special Teaching Methods II course taught by the researcher. Learning together technique, which is one of the cooperative learning methods, was used in the experimental group of the study, whereas traditional group work where principles of cooperative learning were ignored was used in the control group. Prior to the practice, the preservice teachers in the experimental group were given theoretical information about cooperative learning and the learning together technique, which would be used during the group work and it was also explained how groups would be formed, how tasks would be assigned and how activities would be implemented. Particular attention was paid by the researcher to forming heterogeneous groups within the experimental group (4 groups, each with 4 members, $N=16$ ) and the control group (4 groups, each with 4 members, $N=16)$ taking into consideration gender and grade point average. After the groups were determined, some skills included in the Social Studies Teaching Program, namely environmental literacy, political literacy, legal literacy and self-control skills, were assigned to the groups by lot. The groups were told that they would prepare detailed reports defining the skill they were responsible for and teach a class by designing a lesson plan and activity based on the relevant skill. Distribution of the tasks in the experimental group was decided by the group members and in order to enhance group solidarity, the group members shared among themselves roles such as the researcher and the scribe (preparing reports and lesson plans), the material manager (material development and organization), the designer (designing activities) and the presenter (teaching lessons). The groups (in the experimental group) were also asked to keep reflective diaries wich would reflect their views concerning cooperative learning. The lessons taught in the control and experimental groups were evaluated by, excluding the researcher, 5 preservice teachers not included in the groups using PASATPC, taking into consideration the reports and the lesson plans prepared as well as the lectures. By receiving feedbacks from other peers, assessments were made regarding group performances, and interactions between preservice teachers were further encouraged. The process of application was implemented simultaneously in the experimental and control groups and lasted 5 weeks in total.

Findings: The PASATPC posttest mean scores belonging to the communication and assessment and preparing for the course and relating the course subdimensions of the teaching process, were analyzed by using the independent $t$-test. According to the findings obtained, it was observed that posttest mean scores of the experimental and control group preservice teachers exhibited a significant difference in favor of the experimental group in the teaching process and communication and assessment subdimensions. However, a significant difference was not observed in the preparing for the class and relating the course subdimensions although the mean scores of the preservice teachers in the experimental group were higher than those in the control group. The posttest mean scores of the experimental and control group preservice teachers belonging to the classroom management and feedback subdimensions of the TPCPTPRS were analyzed using Mann Whitney $U$ test. When the findings obtained were analyzed, a statistically significant difference was observed in favor of the experimental group between the posttest mean scores of the experimental and control group teachers in the classroom management and feedback subdimensions. When the preservice teachers' views concerning the contribution of cooperative learning to their professional knowledge and skills and their reasons for their views were examined, it was found that cooperative learning contributed to their professional knowledge and skills in preparing and implementing lesson plans, preparing activities, determining and implementing methods and techniques, making assessments and preparing materials. It was understood that thanks to cooperative learning, preservice teachers gained knowledge and experinece regarding preparing lesson plans and activities, determining and implementing methods and techniques suitable for the relevant skill, assessing the teaching occasion and preparing. The preservice teachers proposed as reasons the fact that they were in constant communication, interaction and solidarity with the group members. The preservice teachers added that cooperative learning improved their sense of responsibility, gained them the skills to prepare researches and reports, promoted communication and interaction and developed a favorable attitude towards group work.

Conclusion: In conclusion, it was found that cooperative learning was more effective with regard to the professional knowledge and skills of preservice teachers when compared with the traditional group work. 


\section{Giriş}

Öğretmen yetiştirme eğitimin en önemli işlevleri arasında yer almaktadır (Durmuşçelebi, Yıldız ve Saygı, 2017). Günümüz öğretmen yetiştirme sistemlerinde öğretmenlere nitelik ve yeterlik kazandırmada hizmet öncesi eğitim programları ile hizmet içi eğitim ya da mesleki gelişim etkinlikleri büyük rol üstlenmektedir (Özer, 2008). Öğretmenlik mesleğine hazırlık sürecinin öğretmen eğitimi programlarında başladığı düşünüldüğünde (Baki ve Gökçek, 2007), hizmet öncesi eğitimi hizmet içi eğitimin bütünleyicisi olarak kabul etmek gerekir (Özer, 2008).

Hizmet öncesi eğitimde öğretmen adayları mesleğin gerektirdiği yeterlikleri edinmektedirler. Mesleğin başarılı bir şekilde yerine getirilmesi için öngörülen bilgi, beceri ve tutumları ifade eden yeterlik kavramı (Gündüz, 2012; Özmen, 2013; Şişman, 2009), öğrenimini tamamlayan bir öğretmen adayının mesleki becerilerini açıkça ortaya koymaktadır (Uslu, 2015). Öğretmenlerin ve öğretmen adaylarının kendilerini mesleki açıdan yeterli görme durumları (öz-yeterlik algısı) son yıllarda üzerinde çokça durulan konulardan biridir (Özdemir, 2008). Öz-yeterlik, öğretmenlerin sınıf içindeki davranışlarıyla ilişkili olan, başarısızlık ve zorluklar karşısında kararlılığını etkileyen bir faktördür (Tschannen-Moran ve Woolfolk Hoy, 2001; Tschannen-Moran, Woolfolk Hoy ve Hoy, 1998). Ayrıca öğretmenin etkililiğini şekillendiren önemli bir motivasyon kaynağı (Pendergast, Garvis ve Keogh, 2011), olumlu öğretim davranışları ve öğrenci çıktıları ile ilişkili bir değişkendir (Henson, 2001). Öğretmenlerin yeterlik inancı, öğrenci başarısı için gerekli beceri ve yeteneklere sahip olma inancıdır (Czerniak, 1989). Farklı alanlarda yapılan araştırmalarda öğretmen adaylarının öz-yeterlik algılarının genellikle ortalamanın üzerinde ya da yüksek olduğu tespit edilmiştir (Gökmen ve Ekici, 2018; Işıksal ve Çakıroğlu, 2006; Kutluca, 2018; Recepoğlu ve ibret, 2019; Seferoğlu, 2004; Uyanık Balat, Akman ve Günşen, 2018; Yeşilyurt, 2013). Ancak Kutlu ve Gökdere'nin (2012) çalışmasında sınıf öğretmeni adaylarının öz-yeterlik düzeyleri düşük çıkmıştır. Kaşkaya (2012) öğretmen yeterlikleri ile ilgili yapılan 21 araştırmayı incelemiş, çalışmaların sıklıkla öğretmen adayları üzerinde gerçekleştirildiği, genelde mesleki yeterliklere "olumlu" ya da "iyi derecede" sahip olunduğu sonucuna ulaşmıştır. Fakat bireylerin kendi yeterliklerine ilişkin algılarından hareketle onların mesleki yeterliklere sahip olma düzeylerinin belirlenmesinin uygun bir yöntem olmayacağını, bu çerçevede tek başına nicel yöntemlerin ve anketlerin etkisiz kalacağını, nitel yöntemlere de yer vermenin sağlıklı olacağını ifade etmiştir. Kaşkaya'nın ifadesini destekler şekilde, Recepoğlu ve ỉbret (2019) sosyal bilgiler öğretmen adaylarının mesleki öz-yeterlik algılarını belirlemeye çalıştığı araştırma sonucunda, öğrenci katılımını sağlama, öğretim stratejileri ve sınıf yönetimi boyutlarında 4. sınıfların puan ortalamaları 1, 2 ve 3. sınıftaki öğrencilere göre düşük bulunmuştur. Öte yandan öğretmen adaylarının öğrenci katılımını sağlama ve öğretim stratejileri boyutunda sınıf yönetimi boyutuna göre kendilerini daha az yeterli algıladıkları ortaya çıkmıştır. Literatürde öğretmen adaylarının; ders planı (Derman, 2007; Gündoğdu, Altın, Üstündağ ve Altay, 2018) ve materyal hazırlama (Gündoğdu, Altın, Üstündağ ve Altay, 2018), yöntem ve teknikleri uygun bir şekilde kullanma, etkinlik hazırlama, sınıf yönetimi (Derman, 2007), öğrenci katılımını sağlama (Ünlü, Kaşkaya ve Kızılkaya, 2006) ve değerlendirme (Derman, 2007; Gündoğdu ve diğerleri, 2018) alanlarında yeterli olmadıkları belirlenmiştir. Taşkın ve Hacıömeroğlu'nun (2010) çalışmalarında öğretmen adaylarından bazıları meslek bilgisi derslerini yetersiz bulmuş, buna gerekçe olarak da derslerin işleniş tarzını göstermişlerdir.

Öğrenme bireysel olduğu kadar ortak bir anlayış ve bilgi üretmek için işbirliği yapıldığında ortaya çıkan sosyal bir etkinliktir (Johnson, Johnson ve Smith, 2013). Sosyal etkileşimler yoluyla öğrenme bireyin öğrenmesi ve gelişimi üzerinde önemli bir rol oynamaktadır (Lazarowitz, 2013). 1960'lı yıllarda ilköğretim ve ortaöğretim kurumlarının yanı sıra üniversitelerde de rekabetçi ve bireysel öğrenme hâkim, işbirlikli öğrenme eğitimciler tarafından göz ardı edilirken (Johnson ve Johnson, 2008), yeni öğretim paradigması ile birlikte günümüzde işbirliği içerisinde çalışarak bilginin aktif yapılandırılmasının öğrencilerin beceri ve yeteneklerinin geliştirilmesine yardımcı olduğu anlayışı öne çıkmıştır (Johnson ve diğerleri, 2013). Rekabetçi ve bireysel öğrenme ortamlarında öğrencilerin sınıf arkadaşları ile arasındaki olumsuz ilişkiler bilginin aktif şekilde yapılandırılması ve yeteneklerin geliştirilmesine engel teşkil etmektedir. Hâlbuki öğrencilerin sınıf arkadaşlarını kendi akademik ve kişisel başarıları için engel olmaktan ziyade işbirlikli olarak görmeleri gerekmektedir (Johnson ve diğerleri, 2013). İşbirlikli öğrenme yeni öğretim paradigmasının işevuruk hale geldiği ve öğrenci yeteneğinin gelişiminin desteklendiği bağlamı oluşturmaktadır (Johnson ve diğerleri, 2013). İşbirlikli öğrenme, çeşitli performans düzeyindeki öğrencilerin ortak hedeflere yönelik küçük gruplar halinde birlikte çalıştıkları öğretim yöntemidir (Gholami, 2011; Gokhale, 1995; Johnson ve Johnson, 1992; Kaufman, Sutow ve Dunn, 1997; Slavin, 2014). Öğrenciler birbirlerinin ve kendi öğrenmelerinden sorumlu olduklarından bir öğrencinin başarısı diğer öğrencilerinin başarısına yardımcı olmaktadır (Gokhale, 1995). İşbirlikli öğrenmede öğrencilerin geleneksel öğrenme ortamında sergiledikleri davranışlar değişmekte, gruptaki herkes aktif bir role ve kişisel sorumluluğa sahip olarak görevlerini yerine getirmektedir (Russell, Waters ve Turner, 2014). Jolliffe (2007) işbirlikli grup çalışmalarını geleneksel grup çalışmalardan ayıran iki ana etkenin olumlu bağımlılık ile bireysel sorumluluk 
olduğunu belirtmiştir. Jolliffe, öğrencileri gruplara yerleştirmenin birlikte çalışabilecekleri anlamına gelmediğini, grup üyelerinin hedeflere ulaşmak için birlikte çalışması, birbirleriyle tartışmaları ve çalışmayı anlamaları için birbirlerine yardımcı olmaları gerektiğini vurgulamıştır.

İşbirlikli öğrenme yöntemi; birlikte öğrenme, öğrenci takımları başarı bölümleri, takım destekli bireyselleştirme, takım-oyun-turnuva, işbirlikli okuma ve kompozisyon, jigsaw ve grup araştırması gibi birden fazla tekniği içermektedir (Slavin, 2010). Bu çalışmada "birlikte öğrenme" tekniği kullanıldığından burada yalnızca bu tekniğe değinilmiştir. Birlikte öğrenme tekniği, öncelikle öğretim hedeflerinin belirlenmesi, hedeflere göre grupların oluşturulması ve işbirliğine dayalı olarak çalışmaların yapılmasını kapsamaktır (Sharan, 1999'dan akt. Şimşek, Doymuş ve Karaçöp, 2009). Bu teknikte öğrenciler dört veya beş kişilik gruplar halinde akademik görevler üzerinde birlikte çalışır. Grup üyeleri ne kadar ilerledikleriyle ilgili düzenli tartışmalar yapar. Çalışmanın sonunda her grup çalışmasını öğretmene sunar ve gösterdikleri performansın derecesine bağlı olarak övgü veya ödüller alır (Hendrix, 1999). Sosyal bilgilerde ve diğer alanlarda işbirlikli öğrenme üzerine gerçekleştirilen araştırmalar, bu yöntemlerin ilköğretim ve ortaöğretim düzeyindeki öğrencilerin başarısı (Aubrey-Martinez, 2016; Gholami, 2011; Giraud, 1997; Holliday, 1995; Johnson, Maruyama, Johnson, Nelson ve Skon, 1981; Mattingly ve VanSickle, 1991; Slagle, 2007), tutumu (Arslan ve Zengin, 2016a; Chung-Schickler, 1998; Hevedanlı ve Akbayın, 2006; Ifamuyiwa ve Akinsola, 2008), eleştirel düşünme (Gokhale, 1995) ve sosyal becerileri (Arslan ve Zengin, 2016b; Lavasani, Afzali ve Afzali, 2011; Lavasani, Afzali, Borhanzadeh, Afzali ve Davoodi, 2011; Yılar ve Şimşek, 2016b) üzerinde etkili olduğunu göstermiştir. Üniversite düzeyinde yapılan çalışmalarda ise öğrencilerin öğrenmesi (Lin, 2010), performansı (Jiang, 2014), motivasyonu (Arslan ve Zengin, 2016b; Du, 2012), benlik saygısı (Du, 2012; Slagle, 2007) ve kişilerarası becerileri (Du, 2012) üzerinde olumlu bir etkiye sahip olduğu saptanmıştır. Diğer taraftan işbirlikli öğrenmenin öğretmen adaylarının özyeterlik düzeyini (Scharmann ve Hampton, 1995), eleştirel düşünme (Goyak, 2009) ile iletişim becerilerini (Prastyo, 2017; Sarıgöz, 2017) geliştirdiği de tespit edilmiştir. İşbirlikli öğrenmeye dayalı araştırmaların çoğunun ilköğretim ve ortaöğretim düzeyinde yapılması, üniversite düzeyinde bu konuda sınırlı sayıda deneysel kanıtın olması bu konuda duyulan ihtiyacı ortaya koymaktadır (Gokhale, 1995; Herrmann, 2013). Lyman ve Davidson (2004) öğretmen adaylarının işbirlikli öğrenmeyi sınıf arkadaşlarına ilkokul ve ortaokul öğrencilerine uygun bir içeriği (ya da beceriyi) öğretmek için kullanabileceklerini dile getirmiştir. İşbirlikli öğrenme deneyimleri öğretmen adaylarını öğretmeye hazırlamak için etkili ve motive edici bir kaynaktır (Hillkirk, 1991). Bu araştırmada işbirlikli öğrenmenin sosyal bilgiler öğretmen adaylarının mesleki bilgi ve becerileri üzerindeki etkisi incelenerek ilgili literatüre katkıda bulunmak amaçlanmıştır. Araştırmada öğretmen adayların işbirlikli öğrenmeye yönelik görüşleri de belirlenmiştir.

\section{Yöntem}

\section{Araştırma Modeli}

Araştırma, karma araştırma modellerinden nicel ve nitel verilerin eş zamanlı olarak toplandığı ve ayrı ayrı analiz edildiği, elde edilen sonuçların birlikte yorumlandığı yakınsayan paralel desene göre yürütülmüştür (Creswell ve Clark, 2014). Karma modelin tercih edilmesinin temel nedeni, araştırmanın nicel yöntemlerle ulaşılan sonuçlarını nitel yöntemlerle açıklayarak işbirlikli öğrenmenin öğretmen adaylarının mesleki bilgi ve becerileri üzerindeki etkisinin daha iyi anlaşıımasını sağlamaktır. Araştırmanın nicel boyutunda yarı deneysel desenlerden sontest eşleştirilmiş kontrol gruplu desen uygulanmıştır. Bu desende hazır gruplardan ikisi belli değişkenlere göre eşleştirilmeye çalışılır. Eşleştirilen gruplar işlem gruplarına seçkisiz olarak atanır (Büyüköztürk, Çakmak, Akgün, Karadeniz ve Demirel, 2016). Nitel boyutta ise olgubilim deseni kullanıımıştır. Öğretmen adaylarının işbirlikli öğrenmeye yönelik deneyimleri ele alındığı için olgubilim deseni tercih edilmiştir.

\section{Çalışma Grubu}

Araştırmanın çalışma grubunu 2018-2019 eğitim-öğretim yılında bir devlet üniversitesinin Sosyal Bilgiler Eğitimi Anabilim Dalında son sınıfta öğrenim gören, Özel Öğretim Yöntemleri II dersini alan 32 öğretmen adayı (deney=16; kontrol=16) oluşturmaktadır. Deney ve kontrol grubunun belirlenmesi sürecinde öncelikle ilgili anabilim dalının $A$ ve $B$ şubelerinde öğrenim gören toplam 90 öğretmen adayı cinsiyet ve genel akademik başarı ortalaması değişkenleri üzerinden eşleştirilmeye çalışılmıştır. Grupları deney ve kontrol grubuna seçkisiz olarak atamak için öğrenciler genel akademik not ortalaması (düşük-yüksek) ve cinsiyete (kadın-erkek) göre dört kategori altında sınıflandırılmış, her bir kategoriden birer öğrenci alınarak düşük ve yüksek akademik ortalamaya sahip kadın ve erkek öğrencilerden oluşan 8 grup oluşturulmuştur. Her biri dört kişiden oluşan bu gruplar seçkisiz olarak deney (4 grup) ve kontrol gruplarına (4 grup) atanmıştır.

\section{Veri Toplama Araçları}


İşbirlikli öğrenmenin öğretmen adaylarının mesleki bilgi ve becerileri üzerindeki etkisi Öğretmenlik Uygulaması Dersi Öğretmen Adayı Akran Değerlendirmesi Ölçeği (ÖUDÖAADÖ) kullanılarak tespit edilmiştir. Bektaş, Horzum ve Ayvaz (2010) tarafından geliştirilen ÖUDÖAADÖ için yapılan açımlayıcı faktör analizi sonucunda 5 faktörlü bir yapı elde edilmiştir. Ölçekte yer alan faktörler "öğretim süreci”, "iletişim kurma ve değerlendirme”, "derse hazırlama ve dersi ilişkilendirme", "sınıf yönetimi" ve "geribildirim" şeklindedir. Beşli likert tipinde hazırlanan bu ölçekteki 29 maddenin faktör yük değerleri 0.30-0.86 arasında değişmektedir. Beş faktörün açıkladığı varyans oranı \%50'dir. Ölçeğin geneline ilişkin toplam iç tutarlık katsayısı .92 olarak bulunmuştur. Ölçeğin alt boyutlarına ilişkin iç tutarlılık katsayıları; birinci alt faktör için .81, ikinci alt faktör için .78, üçüncü alt faktör için .78, dördüncü alt faktör için .68 ve beşinci alt faktör için .67 olarak bulunmuştur. Ölçekten alınabilecek en düşük puan 29, en yüksek puan 145'tir. Ölçeğin bu çalışmada hesaplanan Cronbach Alpha değeri ölçeğin geneli için .92 belirlenmiş, alt boyutlar için .60-.91 arasında değişen değerler almıştır. Özdamar'a (1999) göre, Cronbach Alpha güvenirlik katsayısının 0.60-0.80 arasında olması kabul edilebilir düzeyde güvenilir olduğu ve 0.90-1.00 arasında olması çok yüksek düzeyde güvenilir olduğunu ifade etmektedir.

İşbirlikli öğrenmenin uygulandığı deney grubundaki öğretmen adaylarından işbirlikli öğrenmeye ilişkin görüşlerini belirtecekleri yansıtıcı günlük hazırlamaları istenmiştir. Günlüklerde grup çalışması süresinde deneyimledikleri süreç ve durumları (iletişim ve etkileşim kurma, öğretimi planlama, öğretme-öğrenme sürecini yönetme gibi) ifade etmeleri beklenmiştir.

\section{Uygulama}

Çalışma, araştırmacı tarafından verilen Özel Öğretim Yöntemleri II dersinde yürütülmüştür. İlgili ders öğretmen adaylarının alanla ilgili becerilere sahip olma ve bunları geliştirme, alana özgü strateji, yöntem ve teknikleri öğrenme ve uygulamaya dönüştürmeyi amaçlamaktadır. Araştırmanın deney grubunda işbirlikli öğrenme yöntemlerinden birlikte öğrenme tekniği, kontrol grubunda ise işbirlikli öğrenme ilkelerinin dikkate alınmadığı geleneksel grup çalışması uygulanmıştır. Uygulama öncesinde deney grubunda yer alan öğretmen adaylarına işbirlikli öğrenme ile grup çalışmalarında uygulanacak olan birlikte öğrenme tekniği hakkında teorik bilgi sunulmuş, grupların nasıl oluşturulacağı, görevlerin nasıl dağıtılacağı ve etkinliklerin ne şekilde sürdürüleceği açıklanmıştır. Deney (4 kişilik 4 grup) ve kontrol (4 kişilik 4 grup) grubundaki gruplar araştırmacı tarafından cinsiyet ve genel akademik not ortalaması dikkate alınarak heterojen şekilde oluşturulmaya çalışılmıştır. Gruplar belirlendikten sonra Sosyal Bilgiler Öğretim Programında (MEB, 2018) yer alan becerilerden çevre okuryazarlığı, politik okuryazarlık, hukuk okuryazarlığı ve öz denetim becerileri ile ilgili kazanımlar gruplara kura yoluyla dağıtılıı̧tır. Gruplara sorumlu oldukları beceriyi tanımlayan ayrıntılı bir rapor hazırlayacakları, kazanıma dayalı ders planı ve etkinlik tasarlayarak ders anlatımı yapacakları ifade edilmiştir. Deney grubundaki görev dağılımları grup üyeleri tarafından kararlaştırılmış, grup bağımlılığını sağlamak için üyeler kendi aralarında araştırmacı ve kâtip (rapor ve ders planı hazırlama), materyal yöneticisi (materyali geliştirme ve düzenleme), tasarımcı (etkinlik tasarlama) ve sunucu (ders anlatımı) gibi rolleri paylaşmışlardır. Gruplardan (deney grubu) ayrıca işbirlikli öğrenmeye dair görüşlerini yansıtacakları yansıtıcı günlük tutmaları istenmiştir. Deney ve kontrol grubunda gerçekleştirilen ders anlatımları araştırmacının dışında gruplarda yer almayan 5 öğretmen adayı tarafından hazırlanan rapor, ders planı ve ders anlatımı göz önünde bulundurularak ÖUDÖAADÖ kullanılarak değerlendirilmiştir. Diğer akranların da sözlü geribildirimlerde bulunması ile hem grup performanslarına ilişkin değerlendirmeler yapılmış hem de öğretmen adayları arasındaki etkileşim daha fazla teşvik edilmiştir. Uygulama süreci deney ve kontrol grubunda paralel olarak yürütülmüş ve toplam 5 hafta sürmüştür.

\section{Verilerin Analizi}

Araştırmanın nicel boyutunda veriler analiz edilmeden önce verilerin ölçeğin alt boyutlarına göre normal dağılım gösterip göstermediğini belirlemek için Shapiro-Wilks normallik testi yapılmıştır. Verilerin normal dağılım gösterdiği alt boyutlarda bağımsız örneklem t-testi, normal dağılım göstermediği alt boyutlarda Mann Whitney $U$ testi uygulanmıştır. Yapılan ikili karşılaştırmalarda, deney ve kontrol grubundaki grupların ÖUDÖAADÖ'den aldıkları puanların ortalaması sontest olarak kullanılmıştır. Çalışmada aynı koşullar altında altı değerlendirmecinin her bir grubu bağımsız olarak puanlamasına ilişkin elde edilen puanlar arasındaki tutarlılık derecesi Kendall Uyuşum Katsayısı (W) ile hesaplanmış, altı farklı değerlendirmecinin 8 gruba yaptıkları değerlendirmeler arasında istatistiksel olarak anlamlı düzeyde uyum olduğu görülmüştür. Analizlerde anlamlılık düzeyi .05 olarak kabul edilmiştir. Verilerin düzenlenmesi ve analizinde Excel ve SPSS 21 programları kullanılmıştır.

Nitel boyutta, deney grubundaki öğretmen adayları tarafından hazırlanan yansıtıcı günlükler betimsel analiz tekniği kullanılarak çözümlenmiştir. Veriler araştırma soruları ışığında daha önceden belirlenen temalara göre özetlenip yorumlanmıştır. Analiz sürecinde katılımcıların görüşleri literatürden de yararlanılarak belirlenen temalar 
altında düzenlenmiş ve yorumlanmıştır. Katılımcıların görüşlerini çarpıcı biçimde yansıtmak için doğrudan alıntılar yapılmıştır (Yıldırım ve Şimşek, 2016). Alıntılara yer verilirken katılımcının ismi yerine kod numaraları (K1, K2 gibi) kullanılarak kimliği gizli tutulmaya çalışılmıştır. Araştırmanın geçerliğini ve güvenirliğini sağlamak amacıyla, katılımcı görüşlerinden doğrudan alıntılar yapılmış ve nitel araştırma deneyimi ve doktora unvanına sahip olan başka bir araştırmacıdan yardım alınmıştır. Yapılan kodlama ve ulaşılan temalar bu araştırmacı tarafından da kontrol edilerek tutarlılık ve teyit edilebilirliğe gayret edilmiştir.

\section{Bulgular}

Bu bölümde araştırmanın amacı doğrultusunda bulgular sunulmuştur. Öncelikle işbirlikli öğrenmenin öğretmen adaylarının mesleki bilgi ve becerileri üzerindeki etkisi ile ilgili bulgulara, ardından işbirlikli öğrenmeye ilişkin öğretmen adaylarının görüşlerine yer verilmiştir.

Tablo 1. Deney ve Kontrol Gruplarının Öğretim Süreci, İletişim Kurma ve Değerlendirme ile Derse Hazırlama ve Dersi İlişkilendirme Alt Boyutlarına İlişkin Sontest Ortalamalarının Karşılaştırılması

\begin{tabular}{lcccccc}
\hline Boyutlar & Grup & $\mathbf{N}$ & $\overline{\mathbf{X}}$ & Ss & $\mathbf{t}$ & $\mathbf{p}$ \\
\hline Öğretim süreci & Deney & 24 & 33.41 & 3.69 & \multirow{2}{*}{$.85^{*}$} & .006 \\
\hline $\begin{array}{l}\text { Iletişim kurma ve } \\
\text { değerlendirme }\end{array}$ & Kontrol & 24 & 28.95 & 6.68 & & \multirow{2}{*}{000} \\
\hline $\begin{array}{l}\text { Derse hazırlama ve } \\
\text { dersi ilişkilendirme }\end{array}$ & Deney & 24 & 23.62 & 3.53 & $4.65^{*}$ & \\
\hline
\end{tabular}

${ }^{*} \mathrm{p}<.05 ;{ }^{* *} \mathrm{p}>.05 ; \mathrm{N}$ : Her bir grubun (deney=4, kontrol=4) performansı 6 değerlendirmeci tarafından değerlendirilmiştir $(6 \times 4=24)$.

Deney ve kontrol grubu öğretmen adaylarının ÖUDÖAADÖ öğretim süreci, iletişim kurma ve değerlendirme ve derse hazırlama ve dersi ilişkilendirme alt boyutlarına ilişkin sontest puan ortalamaları bağımsız örneklem t-testi ile karşılaştırılarak analiz edilmiştir. Ulaşılan bulgulara göre, deney ve kontrol grubu öğretmen adaylarının sontest ortalamalarının öğretim süreci $(t=2.85, p<.05)$ ve iletişim kurma ve değerlendirme $(t=4.65, p<.05)$ alt boyutlarında deney grubu lehine anlamlı farklılık gösterdiği tespit edilmiştir. Ancak derse hazırlama ve dersi ilişkilendirme alt boyutunda deney grubundaki öğretmen adaylarının sontest ortalamaları kontrol grubundakilere göre yüksek olmasına rağmen istatistiksel olarak anlamlı fark görülmemiştir ( $t=1.94, p>.05)$. Bu durumda, deney grubunda uygulanan işbirlikli öğrenmenin geleneksel grup çalışmasına göre öğretmen adaylarının öğretim süreci ile iletişim kurma ve değerlendirme becerileri üzerinde daha etkili olduğu söylenebilir.

Tablo 2. Deney ve Kontrol Gruplarının Sınıf Yönetimi ve Geribildirim Alt Boyutlarına İlişkin Sontest Ortalamalarının Karşılaştırılması

\begin{tabular}{lcccccc}
\hline Boyutlar & Grup & N & Sıra Ortalaması & Sıra Toplamı & U & p \\
\hline \multirow{2}{*}{ Sınıf yönetimi } & Deney & 24 & 30.88 & 741.00 & 135.000 & $.001^{*}$ \\
& Kontrol & 24 & 18.13 & 435.00 & & \\
& Deney & 24 & 31.85 & 764.50 & 111.500 & $.000^{*}$ \\
\multirow{2}{*}{ Geribildirim } & Kontrol & 24 & 17.15 & 411.50 & & \\
\hline${ }^{*}$ p<.05; N: Her bir grubun (deney=4, kontrol=4) performansı 6 değerlendirmeci tarafından değerlendirilmiştir (6x4=24).
\end{tabular}

Deney ve kontrol grubu öğretmen adaylarının ÖUDÖAADÖ sınıf yönetimi ve geribildirim alt boyutlarına ait sontest puan ortalamaları Mann Whitney $U$ testi ile karşılaştırılarak analiz edilmiştir. Elde edilen bulgular incelendiğinde, deney ve kontrol grubundaki öğretmen adaylarının sontest puan ortalamaları arasında sınıf yönetimi $(U=135.000, p<.05)$ ve geribildirim $(U=111.500, p<.05)$ alt boyutlarında anlamlı fark görülmektedir. Sıra ortalamaları dikkate alındığında, deney grubunda uygulanan işbirlikli öğrenmenin kontrol grubunda yürütülen geleneksel grup çalışmasına kıyasla öğretmen adaylarının sınıf yönetimi ve geribildirim becerileri üzerinde daha etkili olduğu söylenebilir. 
Tablo 3. İşbirlikli Öğrenmenin Mesleki Bilgi ve Becerilere Katkılarına ve Gerekçelerine İlişkin Öğretmen Adaylarının Görüşleri

\begin{tabular}{lllc}
\hline Katkıları & $\boldsymbol{f}$ & Gerekçeler & $\boldsymbol{f}$ \\
\hline Ders planı hazırlama ve uygulama & 8 & Sürekli iletişim ve etkileşim halinde olma & 10 \\
Etkinlik hazırlama & 5 & Yardımlaşma ve dayanışma & 5 \\
Yöntem ve teknikleri belirleme ve uygulama & 4 & & \\
Değerlendirme yapma & 2 & & \\
Materyal hazırlama & 1 & & \\
\hline
\end{tabular}

Öğretmen adayları işbirlikli öğrenmenin; ders planı hazırlama ve uygulama $(f=8)$, etkinlik hazırlama $(f=5)$, yöntem ve teknikleri belirleme ve uygulama $(f=4)$, değerlendirme yapma $(f=2)$ ve materyal hazırlama $(f=1)$ hususlarında mesleki bilgi ve becerilerine katkı sağladığıı ifade etmişlerdir (Tablo 3). İşbirlikli öğrenme sayesinde öğretmen adaylarının ders planı ve etkinlik hazırlama, kazanıma uygun yöntem ve tekniklerin belirlenmesi ve uygulanması, öğretimi değerlendirme ve etkili materyal hazırlama konularında bilgi ve tecrübe sahibi oldukları anlaşılmıştır. Öğretmen adayları bunlara gerekçe olarak da grup üyeleriyle sürekli iletişim ve etkileşim halinde olma $(f=10)$ ile yardımlaşma ve dayanışmayı $(f=5)$ göstermişlerdir. Nitekim katılımcılardan K19 "Ne yapmamız gerektiğini tam olarak bilmiyorduk. Gruptaki arkadaşlarla görüşerek nasıl yapacağımızı kararlaştırdık daha sonra rapor, ders planı ve sunum esnasında yapacağımız etkinlikler için grup arkadaşlarımızla birkaç defa daha görüştük ve daha sonra da kurduğumuz Whatsapp grubu ile de sürekli iletişim halindeydik" sözleriyle grup üyeleri arasındaki iletişim ve etkileşimi, K5 ise "Herkes görevini yerine getirip, whatsapp grubunda paylaşıyordu. Eksik noktalarını onlara düzeltip gönderiyorduk. Eksik kalınan yerleri birlikte halletmeye çalışıyorduk. Bu da grupta dayanışma ortamı olmasını sağlıyordu." diyerek üyeler arasında yardımlaşma ve dayanışmaya vurgu yapmıştır. Öğretmen adaylarından K4 ile K17'nin işbirlikli öğrenmenin mesleki bilgi ve becerilere katkıları ile ilgili görüşlerine aşağıda yer verilmiştir:

"Bu ders sonunda ögrrencilere performans ödevi verirken nelere dikkat edeceğim. Ders öncesinde öğrencileri hedeften haberdar etmeyi, ders planı hazırlamayı, ders planı hazırlarken kazanımla ilgili beceri ve değerleri hangi yöntem ve teknik kullanarak öğrenciye en iyi şekilde öğreteceğimizi öğrenmiş oldum. Ders sonunda öğrencilerin öğrenmelerini öğrencilere değerlendirme soruları sorarak öğrencileri değerlendirmeyi de öğrendim." (K4)

"Eskiden ders planıymış, etkinlikmiş bunları hiç bilmezdim. Şimdi rahatııla ders planı hazırlayabilirim. Hangi kazanıma hangi etkinlik uygun karar verebilirim. Ders esnasında nelere dikkat etmem gerektiğinin farkındayım artık. Yöntem ve tekniklerin kullanımından en azından artık fikir sahibiyim. Teknik ve yöntemlerin seçiminde uygulanmasında faydalarını gördüm. Neyi, nerede, nasıl kullanacağımı az çok biliyorum artık." (K17)

Tablo 4. Öğretmen Adaylarının İşbirlikli Öğrenmeye Yönelik Olumlu Görüşleri

\begin{tabular}{ll}
\hline Görüşler & $\boldsymbol{f}$ \\
\hline Sorumluluk duygusu geliştirme & 8 \\
Araştırma ve rapor hazırlama becerisi kazanma & 6 \\
Illetişim ve etkileşimi arttırma & 5 \\
Grup çalışmasına yönelik olumlu tutum geliştirme & 4 \\
\hline
\end{tabular}

Öğretmen adayları işbirlikli öğrenmenin sorumluluk duygusu geliştirdiğini $(f=8)$, araştırma ve rapor hazırlama becerisi kazandırdığını $(f=6)$, iletişim ve etkileşimi artırdığını $(f=5)$ ve grup çalışmasına yönelik olumlu tutum geliştirdiğini $(f=4)$ belirtmişlerdir (Tablo 4). İşbirlikli öğrenmede olumlu bağımlılığın önemine inanan K16 "Genel olarak kendim için, Grubun içinde olurken sorumluluk bilincim daha çok arttı çünkü sadece kendini düşünmüyorsun, diğer arkadaşlarını da etkiliyorsun. Bunun için bana verilen görevleri eksiksiz bir şekilde yapmaya çalıştım." sözleriyle kendine düşen sorumluluğu daha fazla üstlendiğini dile getirmiştir. Öğretmen adaylarından K13 yapılan bu uygulamadan önce herhangi bir rapor hazırlamadıklarını ifade ederken, K19 "Kendimi artık bir rapor hazırlamada yeterli görüyorum bir rapor hazırlarken nerden bakacağıma hangi makale ve tezlerden nereden nasıl faydalanacağımı biliyorum artık ve kendimi bu konuda yeterli görüyorum." şeklinde görüş belirterek artık rapor hazırlama konusunda kendini yeterli gördüğünü, makale ve tez gibi farklı kaynaklardan nasıl ve ne şekilde yararlanacağını öğrendiğini söylemiştir.

Öğretmen adayları daha önceleri sınıf içerisindeki arkadaşlık bağlarının zayıf ve iletişim düzeyinin düşük olduğunu, ancak işbirlikli öğrenme ile birbirleriyle iletişim ve etkileşim kurabildiklerini ifade etmişlerdir. K3 bu konu ile ilgili düşüncelerini "Işsbirlikli grup çalışmasındaki arkadaşlarımı önceden fazla tanımıyordum ama işbirlikli çalışma yöntemiyle grup içerisindeki arkadaşları tanımaya iyi bir iletişim onlarla kurmaya başladım." şeklinde belirtmiştir. Öğretmen adaylarından bazıları yapılan bu uygulama sayesinde grup çalışmalarının etkili ve verimli olduğunun farkına 
vardıklarını dile getirmişlerdir. Bu kapsamda K6 "Gerçekten bu yöntem çok etkili yani nasıl desem ben önceden arkadaşlarla bir ödev yapmayı sevmezdim. Grup şeklinde sunumlar yapmazdım bundan sonra hep grupla çalışma yapacağım gerçekten de grupla çalışmak çok eğlenceli aynı zamanda çok eğitici bir durum." diyerek grup çalışmasına ilişkin geliştirdiği olumlu tutumdan söz etmiştir.

\section{Sonuç, Tartışma ve Öneriler}

Yükseköğretimde öğretme ve öğrenme anlayışının değişmesiyle birlikte aktif öğrenme pedagojide odak haline gelmiştir (Burke, 2011). İşbirlikli öğrenme okul öncesi dönemden yükseköğretime kadar farklı sınıf düzeyleri ve konu alanlarında öğrenciler arasında öğrenme ile sosyalleşmeyi destekleyen pedagojik bir uygulama olarak dikkat çekmiştir (Gillies, 2016). Bu çalışmada işbirlikli öğrenme yöntemlerinden biri olan birlikte öğrenme tekniğinin sosyal bilgiler öğretmen adaylarının mesleki bilgi ve becerileri üzerindeki etkisi incelenmiştir. Ayrıca öğretmen adayların işbirlikli öğrenmeye yönelik görüşleri belirlenmiştir.

Çalışmanın bulgularına göre, birlikte öğrenme tekniğinin uygulandığı deney grubunun sontest puan ortalamalarının geleneksel grup çalışmasının yürütüldüğü kontrol grubuna göre daha yüksek olduğu bulunmuştur. İşbirlikli öğrenmenin geleneksel grup çalışmasına göre öğretmen adaylarının mesleki bilgi ve becerilerden iletişim kurma ve değerlendirme, sınıf yönetimi, geribildirim, derse hazırlama ve dersi ilişkilendirme gibi beceriler üzerinde daha etkili olduğu tespit edilmiştir. Deney grubundaki öğretmen adaylarının hazırlamış oldukları yansıtıcı günlüklerin incelenmesi sonucunda ulaşılan bulgular bu sonucu destekler niteliktedir. Yapılan incelemelerde işbirlikli öğrenmenin öğretmen adaylarının; ders planı hazırlama ve uygulama, etkinlik ve materyal hazırlama, yöntem ve teknikleri belirleme ve uygulama ve değerlendirme yapma konularında mesleki bilgi ve becerilerine katkı sağladığı belirlenmiştir. Literatür incelendiğinde, işbirlikli öğrenmenin geleneksel grup çalışmasına göre öğrencilerin başarısı (Kardaş, 2014) ve bilimsel süreç becerileri (Bozdoğan, Taşdemir ve Demirbaş, 2006) üzerinde etkili bir yöntem olduğu ortaya çıkmıştır. Alanyazında öğretmen adayları üzerinde yapılan çalışmalarda, işbirlikli öğrenmenin öğretmen adaylarını eğitme ve motive etmede etkili bir yöntem olarak benimsendiği, işbirlikli öğrenmeye dayalı öğretmenlik deneyimlerinin öğretici değerinin takdir edildiği görülmüştür (Veenman, van Benthum, Bootsma, van Dieren ve van der Kemp, 2002). Scharmann ve Hampton (1995) işbirlikli öğrenme ile öz-yeterlik inancı arasındaki ilişkiyi incelemiş, işbirlikli öğrenmenin öğretmen adaylarının öz-yeterlik düzeyini olumlu yönde etkilediğini ortaya koymuştur. Erdem (2009) öğretmen adayları üzerinde gerçekleştirdiği araştırma sonucunda, öğretmen adaylarının işbirlikli öğrenmenin entegre edildiği derslere yönelik tutumlarının olumlu olduğu, bu yöntemin öğrenme sürecini desteklediği saptanmıştır. Benzer doğrultuda Erdamar ve Demirel (2010) ile Şimşek, Örten, Topkaya ve Yıllar'ın (2014) araştırma bulguları işbirlikli öğrenmenin öğretmen adaylarının öğretmenlik becerilerinin gelişmesine katkı sağladığını göstermektedir. İşbirlikli öğrenme öğretmen adaylarının kendilerini bir öğretmen olarak görmelerine yardımcı olmaktadır (Turaçoğlu, Alpat ve Ellez, 2013). Bu araştırmada öğretmen adayları işbirlikli öğrenmenin mesleki bilgi ve becerilerine katkısına gerekçe olarak grup üyeleriyle sürekli iletişim ve etkileşim halinde olmayı, yardımlaşma ve dayanışmayı göstermişlerdir. Yılar ve Şimşek'in (2016a) çalışmasında işbirlikli öğrenme yöntemlerinin öğrenme ve başarıyı olumlu etkilediğini düşünen öğrenciler bunun nedenini grupla birlikte çalışma ve grup üyeleriyle karşılıklı yardımlaşmaya bağlamışlardır. İşbirlikli öğrenmede grup hedefleri gruba bağlıı̆ın ve karşııılı yardımlaşmanın artmasına yol açmakta (Slavin, Hurley ve Chamberlain, 2003), iletişim ve etkileşimi desteklemektedir (Bouas, 1996; Erdem, 2009; Lin, 2010; Prastyo, 2017; Sarıgöz, 2017).

Araştırma ile elde edilen bulgular arasında, işbirlikli öğrenmenin öğretmen adaylarının sorumluluk duygusunu geliştirdiği, iletişim ve etkileşimini artırdığı, grup çalışmasına yönelik olumlu tutum geliştirmelerini sağladığı ve onlara araştırma ve rapor hazırlama becerisi kazandırdığı bulgusu yer almaktadır. İşbirlikli öğrenme, öğrencilerin ortak bir amaç için birlikte çalıştıkları, etkileşim ve grup süreçlerini vurgulayan, her grup üyesinin kendi öğrenmesi ile birlikte diğer grup üyelerinin de öğrenmesinden sorumlu olduğu bir öğretim yöntemidir (Ruys, Van Keer ve Alterman, 2012, s. 350). Çeşitli araştırmalarda işbirlikli öğrenmenin öğrencilerin sorumluluk duygusunu (Arslan ve Zengin, 2016b; Er, 2017; Şimşek ve diğerleri, 2014) ve iletişimini geliştirdiği (Ocak ve Küçükilhan, 2014; Şimşek ve diğerleri, 2014), araştırma bilgi ve becerilerini artırdığı (Şimşek ve diğerleri, 2014) belirlenmiş, öğrencilerin grup çalışmalarını olumlu karşıladıkları görülmüştür (Arslan ve Zengin, 2016b; Ocak ve Küçükilhan, 2014).

Sonuç olarak, geleneksel grup çalışmasıyla karşılaştırıldığında işbirlikli öğrenmenin öğretmen adaylarının mesleki bilgi ve becerileri üzerinde daha fazla etkili olduğu saptanmıştır. Bununla birlikte öğretmen adaylarının işbirlikli öğrenmeye yönelik görüşlerinin büyük ölçüde olumlu yönde olduğu görülmüştür. Çalışma bulgularına dayalı olarak ulaşılan sonuçlar ışığında şu öneriler sunulabilir: 
1. İşbirlikli öğrenmenin öğretmen adaylarının mesleki bilgi ve becerileri üzerindeki etkisini ortaya koyan daha fazla deneysel araştırmalar yapılabilir.

2. Çalışmada işbirlikli öğrenme yöntemlerinden birlikte öğrenme tekniği kullanılmıştır. ileriki araştırmalarda işbirlikli öğrenme yönteminin farklı teknikleri de kullanılabilir.

3. Çalışmada ortaya konan işbirlikli öğrenmenin mesleki bilgi ve becerilere katkısından ve literatürde bu alanda görülen ihtiyaçtan hareketle öğretmenlik meslek derslerinde işbirlikli öğrenmeye dayalı etkinliklere yer verilmelidir.

\section{Kaynakça}

Arslan, A., ve Zengin, R. (2016a). İşbirlikli öğrenme yönteminin fen öğretimi laboratuar uygulamaları dersine yönelik öğrencilerin tutumlarına etkisi. İnönü Üniversitesi Eğitim Fakültesi Dergisi, 17(2), 37-49.

Arslan, A., ve Zengin, R. (2016b). İşbirlikli öğrenme yönteminin bilimsel ve sosyal beceriler üzerindeki etkisi. Adıyaman Üniversitesi Eğitim Bilimleri Dergisi, 6(1), 23-45.

Aubrey-Martinez, C. A. (2016). Cooperative learning activities in social studies classrooms and the effect on selfdetermination for students with and without individualized education programs (IEPS). Yayımlanmamıs doktora tezi. Wayne State University, USA.

Baki, A., ve Gökçek, T. (2007). Matematik öğretmeni adaylarının benimsedikleri öğretmen modeline ilişkin bazı ipuçları. Hacettepe Üniversitesi Eğitim Fakültesi Dergisi, 32, 22-31.

Bektaş, M., Horzum, M. B., ve Ayvaz, A. (2010). “Öğretmenlik uygulaması dersi öğretmen adayı akran değerlendirme ölçeği” geliştirme çalışması. E-Journal of New World Sciences Academy Education Sciences, 5(3), 1272-1280.

Bouas, M. J. (1996). Are we giving cooperative learning enough attention in preservice teacher education?. Teacher Education Quarterly, 23(4), 45-58.

Bozdoğan, A. E., Taşdemir, A., ve Demirbaş, M. (2006). Fen bilgisi öğretiminde işbirlikli öğrenme yönteminin öğrencilerin bilimsel süreç becerilerini geliştirmeye yönelik etkisi. İnönü Üniversitesi Eğitim Fakültesi Dergisi, 7(11), 23-36.

Burke, A. (2011). Group work: How to use groups effectively. Journal of Effective Teaching, 11(2), 87-95.

Büyüköztürk, Ş., Çakmak, E. K., Akgün, Ö. E., Karadeniz, Ş., ve Demirel, F. (2016). Bilimsel araştırma yöntemleri (21. Baskı). Ankara: Pegem Akademi Yayıncılık.

Chung-Schickler, G. C. (1998). The effect of cooperative learning on the attitudes toward science and the achievement of students in a non-science majors' general biology laboratory course at an urban community college. Yayımlanmamış doktora tezi. Florida International University, USA.

Czerniak, C. M. (1989). An investigation of the relationships among science teaching anxiety, self-efficacy, teacher education variables, and instructional strategies. Yayımlanmamış doktora tezi. Ohio State University, Columbus.

Creswell, J. W., ve Clark, V. L. P. (2014). Karma yöntem araştırmaları tasarımı ve yürütülmesi (Çev. Ed. Y. Dede ve S. B. Demir). Ankara: Anı Yayıncılık.

Derman, A. (2007). Kimya öğretmeni adaylarının öz yeterlik algıları ve öğretmenlik mesleğine yönelik tutumları. Yayımlanmamış doktora tezi. Selçuk Üniversitesi, Konya.

Du, Y. (2012). Cooperative learning in college English class in Chinese context. Contemporary English Teaching and Learning in Non-English-Speaking Countries, 1(1), 78-94.

Durmuşçelebi, M., Yıldız, N., ve Saygı, E. (2017). Öğretmen adaylarının öğretmenlik mesleğine ilişkin tutumlarının bazı değişkenler açısından incelenmesi. OPUS - Uluslararası Toplum Araştırmaları Dergisi, 7(12), 8-32.

Er, H. (2017). The impact of teaching the subjects under "science in time" unit in the social studies class in the 7th grade using jigsaw technique on the academic success of the students. Universal Journal of Educational Research, 5(5), 838-847.

Erdamar, G. K., ve Demirel, H. (2010). Öğretmen adaylarının grup çalışmalarına ilişkin algıları. Ahi Evran Üniversitesi Eğitim Fakültesi Dergisi, 11(3), 205-223. 
Erdem, A. (2009). Preservice teachers' attitudes towards cooperative learning in mathematics course. Procedia Social and Behavioral Sciences, 1, 1668-1672.

Gholami, G. (2011). The importance of cooperative learning on academic achievement. Journal of American Science, 7(12), 596-599.

Gillies, R. M. (2016). Cooperative learning: Review of research and practice. Australian Journal of Teacher Education, 41(3), 39-54.

Giraud, G. (1997). Cooperative learning and statistics instruction, Journal of Statistics Education, 5(3). [Çevrim-içi: https://tandfonline.com/doi/pdf/10.1080/10691898.1997.11910598?needAccess=true], Erişim tarihi: 16 Şubat 2019.

Gokhale, A. A. (1995). Collaborative learning enhances critical thinking. Journal of Technology Education, 7(1), 22-30.

Goyak, A. M. (2009). The effects of cooperative learning techniques on perceived classroom environment and critical thinking skills of preservice teachers. Yayımlanmamış doktora tezi. Liberty University, USA.

Gökmen, A., ve Ekici, G. (2018). Biyoloji öğretmen adaylarının öğretmen öz-yeterlik algı düzeyleri ile mesleki kaygıları arasındaki ilişkinin incelenmesi. Anadolu Öğretmen Dergisi, 2(2), 17-28.

Gündoğdu, K., Altın, M., Üstündağ, N., ve Altay, B. (2018). Öğretmen adayları öğretmenlik uygulamasında yeterli mi? (Bir olgubilim çalışması). Adnan Menderes Üniversitesi Sosyal Bilimler Enstitüsü Dergisi, 5(1), 150-166.

Gündüz, H. B. (2012). Bir meslek olarak öğretmenlik. M. D. Karslı (Ed.). Eğitim bilimine giriş içinde (s. 217-240). Ankara: Pegem Akademi.

Hendrix, J. C. (1999). Connecting cooperative learning and social studies. The Clearing House, 73(1), 57-60.

Henson, R. K. (2001). Relationships between preservice teachers' self-efficacy, task analysis, and classroom management beliefs. Paper presented at the annual meeting of the Southwest Educational Research Association, New Orleans, LA.

Herrmann, K. J. (2013). The impact of cooperative learning on student engagement: Results from an intervention. Active Learning in Higher Education, 14(3), 175-187.

Hevedanlı, M., ve Akbayın, H. (2006). Biyoloji öğretiminde işbirlikli öğrenme yönteminin başarı, hatırda tutma ve derse yönelik tutum üzerindeki etkileri. Dicle Üniversitesi Ziya Gökalp Eğitim Fakültesi Dergisi, 6, 21-31.

Hillkirk, K. (1991). Cooperative learning in the teacher education curriculum. Education, 111(4), 479-482.

Holliday, D. C. (1995). The effects of the cooperative learning strategy jigsaw II on academic achievement and crossrace relationships in a secondary social studies classroom. Yayımlanmamış doktora tezi. University of Southern Mississippi, USA.

Ifamuyiwa, S.A., ve Akinsola, M.K. (2008). Improving senior secondary school students' attitude towards mathematics through self and cooperative-instructional strategies. International Journal of Mathematical Education in Science and Technology, 39(5), 569-585.

Işıksal, M., ve Çakıroğlu, E. (2006). İlköğretim matematik öğretmen adaylarının matematiğe ve matematik öğretimine yönelik öz yeterlik algıları. Hacettepe Üniversitesi Eğitim Fakültesi Dergisi, 31, 74-84.

Jiang, B. (2014). Web-based cooperative learning in college chemistry teaching. International Journal of Emerging Technologies in Learning, 9(2), 45-47.

Johnson, D. W., ve Johnson, R. T. (1992). Approaches to implementing cooperative learning in the social studies classroom. R. J. Stahl ve R. L. VanSickle (Ed.). Cooperative learning in the social studies classroom: An invitation to social study içinde (s. 44-51). Washington, DC: National Council for the Social Studies.

Johnson, D. W., ve Johnson, R. T. (2008). Social interdependence theory and cooperative learning: The teacher's role. R. M. Gillies, A. F. Ashman ve J. Terwel (Ed.). The teacher's role in implementing cooperative learning in the classroom içinde (s. 10-37), New York: Springer.

Johnson, D. W., Johnson, R. T., ve Smith, K. A. (2013). Cooperative learning and individual student achievement in secondary schools. J. E. Pederson ve A. D. Digby (Ed.). Secondary schools and cooperative learning: Theories, models, and strategies içinde (s. 3-54). New York: Routledge. 
Johnson, D. W., Maruyama, G., Johnson, R., Nelson, D., ve Skon, L. (1981). Effects of cooperative, competitive, and individualistic goal structures on achievement: A meta-analysis. Psychological Bulletin, 89(1), 47-62.

Jolliffe, W. (2007). Cooperative learning in the classroom: Putting it into practice. London: Paul Chapman Publishing.

Kardaş, M. N. (2014). İş birlikli ve geleneksel grup çalışmasının dil bilgisi öğretiminde akademik başarıya etkisi. Turkish Studies, 9(8), 603-622.

Kaşkaya, A. (2012). Öğretmen yeterlikleri kapsamında yapılan araştırmaların konu amaç yöntem ve sonuçları açısından değerlendirilmesi. Kuram ve Uygulamada Eğitim Bilimleri, 12(2), 789-805.

Kaufman, D., Sutow, E., ve Dunn, K. (1997). Three approaches to cooperative learning in higher education. Canadian Journal of Higher Education, 27(2/3), 37-66.

Kutlu, N., ve Gökdere, M. (2012). Öğretmen adaylarının fen öğretimine yönelik tutumlarının ve özyeterlik inanç düzeylerinin incelenmesi. X. Ulusal Fen Bilimleri ve Matematik Eğitimi Kongresi, Niğde, Türkiye.

Kutluca, A. Y. (2018). Öğretmen öz-yeterliğinin motivasyon ve epistemolojik ve pedagojik inanç sistemleri açısından incelenmesi. Cumhuriyet Uluslararası Eğitim Dergisi, 7(2), 175-192.

Lavasani, M.G., Afzali, L., ve Afzali, F. (2011). Cooperative learning and social skills. Cypriot Journal of Educational Science, 4, 186-193.

Lavasani, M. G., Afzali, L., Borhanzadeh, S., Afzali, F., ve Davoodi, M. (2011). The effect of cooperative learning on the social skills of first grade elementary school girls. Procedia Social and Behavioral Sciences, 15, 1802-1805.

Lazarowitz, R. (2013). Learning science in cooperative modes in junior- and senior-high schools cognitive and affective outcomes. J. E. Pederson ve A. D. Digby (Ed.). Secondary schools and cooperative learning: Theories, models, and strategies içinde (s. 185-227). New York: Routledge.

Lin, L. L. (2010). Perspectives of teachers and students toward cooperative learning jigsaw tasks in Taiwanese EFL classrooms. Yayımlanmamış doktora tezi. Alliant International University, USA

Lyman, F., ve Davidson, N. (2004). Cooperative learning in preservice teacher education at the University of Maryland. E. G. Cohen, C. M. Brody ve M. Sapon-Shevin (Ed.). Teaching cooperative learning: The challenge for teacher education içinde (s. 83-95). Albany, NY: State University of New York Press.

Mattingly, R. M., ve VanSickle, R. L. (1991). Cooperative learning and achievent in social studies: jigsaw II. Social Education, 55(6), 392-395.

MEB. (2018). Sosyal bilgiler dersi öğretim programı (ilkokul ve ortaokul 4, 5, 6 ve 7. sınıflar). [Çevrim-içi: http://mufredat.meb.gov.tr/ProgramDetay.aspx?PID=354], Erişim tarihi: 29 Mart 2019.

Ocak, G., ve Küçükilhan, S. (2014). İşbirliğine dayalı öğrenci takımları-başarı bölümleri (ÖTBB) tekniğinin sosyal bilgiler dersindeki akademik başarıya ve kalıcılığa etkisi. e-Uluslararası Eğitim Araştırmaları Dergisi, 5(4), 17-40.

Özdamar, K. (1999). Paket programlar ile istatistiksel veri analizi. Eskişehir: Kaan Kitabevi.

Özdemir, S. M. (2008). Sınıf öğretmeni adaylarının öğretim sürecine ilişkin öz-yeterlik inançlarının çeşitli değişkenler açısından incelenmesi. Kuram ve Uygulamada Eğitim Yönetimi, 54, 277-306.

Özer, B. (2008). Öğretmenlerin mesleki gelişimi. A. Hakan (Ed.). Öğretmenlik meslek bilgisi alanındaki gelişmeler içinde (s. 195-216). Eskişehir: Anadolu Üniversitesi Açıköğretim Fakültesi.

Özmen, H. (2013). Öğretmenlik mesleği yeterlikleri. H. Özmen ve D. Ekiz (Ed.). Eğitim bilimine giriş içinde (s. 199-212). Ankara: Pegem Akademi.

Pendergast, D., Garvis, S., ve Keogh, J. (2011). Pre-service student-teacher self-efficacy beliefs: An insight into the making of teachers. Australian Journal of Teacher Education, 36(12), 46-58.

Prastyo, Y. D. (2017). Effects of cooperative learning on student teachers' communicative competence in Indonesia. Yayımlanmamış doktora tezi. University of Limerick, Ireland.

Recepoğlu, S., ve ỉbret, B. Ü. (2019). Mesleki özyeterliğe yönelik sosyal bilgiler öğretmen adaylarının görüşleri. Uluslararası Sosyal Araştırmalar Dergisi, 12(62), 1091-1097. 
Russell, W. B., Waters, S., ve Turner, T. N. (2014). Essentials of middle and secondary social studies. New York, NY: Routledge.

Ruys, I., Van Keer, H., ve Aelterman, A. (2012). Examining pre-service teacher competence in lesson planning pertaining to collaborative learning. Journal of Curriculum Studies, 44(3), 349-379.

Sarıgöz, O. (2017). An analytical study on views of teacher candidates about cooperative learning approach. The Journal of International Social Research, 10(49), 491-497.

Scharmann, L. C., ve Hampton, C. M. O. (1995). Cooperative learning and preservice elementary teacher science selfefficacy. Journal of Science Teacher Education, 6(3), 125-133.

Seferoğlu, S. S. (2004). Öğretmen adaylarının öğretmen yeterlilikleri açısından kendilerini değerlendirmeleri. Hacettepe Üniversitesi Eğitim Fakültesi Dergisi, 26, 131-140.

Slavin, R. E., Hurley, E. A., ve Chamberlain, A. (2003). Cooperative learning and achievement: Theory and research. W. M. Reynolds ve G. E. Miller (Ed.). Handbook of psychology içinde (s. 177-198). New York: John Wiley \& Sons.

Şimşek, U., Doymuş, K., ve Karaçöp, A. (2009). Yükseköğretimde eğitim gören öğrencilerin demokratik tutumlarına jigsaw ve birlikte öğrenme tekniklerinin etkisi. Atatürk Üniversitesi Sosyal Bilimler Enstitüsü Dergisi, 13(1), 167176.

Şimşek, U., Örten, H., Topkaya, Y., ve Yıllar, B. (2014). Sosyal bilgiler öğretmen adaylarının işbirlikli öğrenme teknikleri hakkındaki görüşleri. Türkiye Sosyal Araştırmalar Dergisi, 18(1), 231-257.

Şişman, M. (2009). Öğretmen yeterlikleri: Modern bir söylem ve retorik. Inönü Üniversitesi Eğitim Fakültesi Dergisi, 10(3), 63-82.

Slagle, D. R. (2007). The use of cooperative learning to promote academic achievement, self-esteem, and inter-group relations in a high school social studies class. Yayımlanmamış yüksek lisans tezi. Defiance College, USA.

Slavin, R. E. (2010). Co-operative learning: What makes group-work work?. H. Dumont, D. Istance, ve F. Benavides (Ed.). The nature of learning: using research to inspire practice içinde (s. 161-178). Paris: OECD Publishing.

Slavin, R. E. (2014). Cooperative learning and academic achievement: Why does groupwork work?. Anales de Psicología, 30(3), 785-791

Taşkın, Ç. Ş., ve Hacıömeroğlu, G. (2010). Meslek bilgisi derslerinin öğretmen adaylarının profesyonel gelişimindeki önemi. Pamukkale Üniversitesi Eğitim Fakültesi Dergisi, 28, 165-174.

Tschannen-Moran, M., ve Woolfolk Hoy, A. (2001). Teacher efficacy: Capturing an elusive construct. Teaching and Teacher Education, 17, 783-805.

Tschannen-Moran, M., Woolfolk Hoy, A., ve Hoy, W. K. (1998). Teacher efficacy: Its meaning and measure. Review of Educational Research, 68(2), 202-248.

Turaçoğlu, İ., Alpat, Ş., ve Ellez, A. M. (2013). Effects of jigsaw on teaching chemical nomenclature. Education and Science, 38(167), 256-272.

Uyanık Balat, G., Akman, B., ve Günşen, G. (2018). Fen eğitimine karşı tutum, öz yeterlilik algısı ve bilişsel harita bulguları. Mersin Üniversitesi Eğitim Fakültesi Dergisi, 14(2), 756-777.

Veenman, S., van Benthum, N., Bootsma, D., van Dieren, J. ve van der Kemp, N. (2002). Cooperative learning and teacher education. Teaching and Teacher Education, 18, 87-103.

Yeşilyurt, E. (2013). Öğretmen adaylarının öğretmen öz-yeterlik algıları. Elektronik Sosyal Bilimler Dergisi, 12(45), 88104.

Yılar, M. B., ve Şimşek, U. (2016a). Sosyal bilgiler dersinde farklı işbirlikli öğrenme yöntemlerinin uygulamalarına ilişkin öğrenci görüşleri. Dicle Üniversitesi Ziya Gökalp Eğitim Fakültesi Dergisi, 29, 375-394.

Yılar, M. B., ve Şimşek, U. (2016b). Sosyal bilgiler dersinde farklı işbirlikli öğrenme uygulamalarının sosyal beceriler üzerindeki etkileri. Ahi Evran Üniversitesi Kırşehir Eğitim Fakültesi Dergisi, 17(3), 835-854.

Yıldırım, A., ve Şimşek, H. (2016). Sosyal bilimlerde nitel araştırma yöntemleri (10. Baskı). Ankara: Seçkin Yayıncılık. 
Uslu, S. (2015). Sosyal bilgiler öğretmenlerinin yeterlikleri. C. Dönmez ve K. Yazıcı (Ed.). Sosyal bilgiler öğretimi içinde (s. 59-91). Ankara: Pegem Akademi.

Ünlü, i., Kaşkaya, A., ve Kızılkaya, M. F. (2017). Sosyal bilgiler öğretmen adaylarının öz-yeterlik inançlarının çeşitli değişkenler açısından incelenmesi. Ahi Evran Üniversitesi Kırşehir Eğitim Fakültesi Dergisi (KEFAD), 18(2), 651668. 